\title{
NSF 'should help fund private observatories'
}

Washington. The US National Science Foundation (NSF) should pay for new instrumentation at privately operated telescopes in exchange for access to these telescopes for outside astronomers, according to a panel of the National Research Council.

Such an arrangement, says the report, would be the best way of dealing with a pending cash crisis in US astronomy. Although many new public and private telescopes are due to come on-line over the next few years, the prospects of more money to equip or operate them are slim.

If the programme has to proceed with flat funding, the panel says, most of the telescopes operated by the National Optical Astronomy Observatories (NOAO) at the Kitt Peak National Observatory in Arizona, as well as most of the support services provided by NOAO headquarters in nearby Tucson, should close in order to release funds for other facilities.

The report - prepared at the request of the NSF by a panel chaired by Richard McCray of the University of Colorado was released last week at the annual meeting of the American Astronomical Society (AAS) at Tucson, Arizona.

Details of how the arrangement could work are still unclear. But astronomers from the private facilities and users of the statefunded NOAO promised to hammer them out with the NSF over the next few months, that the discipline can present a united front to Congress in appealing for more cash.

The McCray panel also outlines three funding options for the NSF's optical and infrared astronomy programme as it adjusts to supporting the 50 per cent US share in the new international Gemini telescopes being built in Hawaii and Chile. If some of the Kitt Peak telescopes were to be closed, then the Gemini, the Cerro Tololo Inter-American Observatory (CTIO) in Chile, and the two largest telescopes at Kitt Peak could then be properly funded, the panel says.

But the McCray panel warns that this plan would eliminate 40 per cent of the telescope access time available to US astronomers. Arguing that "the cost in human, educational and scientific terms [would] be unacceptably high", it also puts forward a second option, under which the NSF would provide an extra $\$ 5.5$ million a year to operate Gemini. NOAO in Tucson would still need to be slimmed down, "but the consequences for the community would not be so draconian", it says.

Under a third - and preferred - option, the NSF would provide an extra $\$ 10$ million a year to fund both Gemini and an expanded version of the programme to win access to private telescopes for NSF-supported astronomers by funding instruments for them.

McCray is optimistic that astronomers could use the report's arguments to win more money in 1997 and 1998 when Gemini will come on-stream and the funding crisis comes to a head. "Everyone will be deeply disappointed if we only get flat funding," he said. "I'm certain we can do better than that."

But others were less sanguine. Sandra

\section{IMAGE UNAVAILABLE FOR COPYRIGHT REASONS}

(see Nature 372, 494; 1994).

The McCray panel says that the NSF can start to build a new relationship with independent observatories immediately, by diverting into the astronomy budget the \$2 million a year that it already spends under an advanced technology programme on developing new astronomy instruments, and arranging for open access to these instruments. The arrangement could be expanded later, as more money became available, the panel says.

It remains to be seen how strongly the proposal will unite the two wings of the community - those with access to good private facilities, and those dependent on the NOAO.

Even as it describes the pain which the NOAO cutbacks in its flat-funding option would cause, the McCray report is scathing about the NOAO support

Faber of the University of California, Santa Cruz - whose arguments for radical change at the NOAO, including the privatization of Kitt Peak, have been partially endorsed by the panel - says that the NSF's astronomy budget "seems poised to decline".

Sidney Wolff, director of the NOAO, says that the attitude of the Republicandominated Congress towards basic research may be more influential than the report in determining the future of funding for astronomy. Some astronomers have been encouraged by the strong belief of Robert Walker (Republican, Pennsylvania), the new chair of the Science Committee in the House of Representatives, that the NSF should return to its roots as a basic science agency

\section{US Congress targets research facilities}

Washington. Support for large US research facilities from the National Science Foundation (NSF) and National Aeronautics and Space Administration (NASA) are expected to be early victims of moves by the Republican-dominated Congress to trim the budget for the 1995 financial year (which started on 1 October 1994).

But other research programmes seem likely to get off lightly in a rescission package being put together as the Republicans' first effort to show that they are serious about public-spending cuts.

Robert Livingston (Republican, Louisiana), chairman of the House of Representatives Appropriations Committee, has asked individual subcommittees to find out how much they can save from the budgets agreed last autumn for this year.

The subcommittee that oversees NSF and NASA is expected to hold a hearing to discuss possible savings before the end of the month, and to rescind most of the $\$ 250$ million that had been allocated this year for the NSF to spend on new university laboratories and $\$ 400$ million for NASA wind tunnel construction. Both programmes are vulnerable because they have long lead times - none of the money has yet been spent and were never supported by the Clinton administration.

Officials at the NSF, which last year won an exceptional 14 per cent increase in its $\$ 3$ billion budget, hope that the panel, chaired by Jerry Lewis (Republican, California), will be content with the facilities rescission, and will not seek cuts from either education or research programmes at NSF. The 1995 rescission bill is likely to be passed by the House in April, by which time the attention of appropriators will have moved on to 1996.

C. $M$. 